\title{
Assessments of $\mathrm{CO}_{2}$ Assimilation on a Per-leaf-area Basis are Related to Total Leaf Area
}

\author{
Timothy L. Righetti ${ }^{1}$, Carmo Vasconcelos, and David R. Sandrock \\ Department of Horticulture, Oregon State University, Corvallis, OR 97331 \\ Samuel Ortega-Farias and Yerko Moreno \\ Facultad de Ciencias Agrarias, University of Talca, Talca, Chile \\ Francisco J. Meza \\ Departamento de Fruticultura y Enologia, Pontificia Universidad Catolica de Chile, Santiago, Chile
}

\begin{abstract}
Additional Index words. developmental stage, intercept corrections, leaf age, leaf area, ratio-based efficiency, regression models, slope-based efficiency

Abstract. Net photosynthetic rates often are dependent on leaf size when expressed on a leaf-area basis $\left(\mathrm{CO}_{2}\right.$ assimilation as $\left.\mu \mathrm{mol} \cdot \mathrm{m}^{-2} \cdot \mathrm{s}^{-1}\right)$. Therefore, distinguishing between leaf-size-related and other causes of differences in net photosynthetic rate cannot be determined when data are presented on a leaf-area basis. From a theoretical perspective, $\mathrm{CO}_{2}$ assimilation expressed on a leaf-area basis $\left(\mu \mathrm{mol} \cdot \mathrm{m}^{-2} \cdot \mathrm{s}^{-1}\right)$ will be independent of leaf area only when total net $\mathrm{CO}_{2}$ assimilation (leaf $\mathrm{CO}_{2}$ assimilation as $\mu \mathrm{mol} \cdot \mathrm{s}^{-1}$ ) is linearly related to leaf area and the function describing this relationship has a nonzero $y$ intercept. This situation was not encountered in the data sets we evaluated; therefore, ratio-based estimates of $\mathrm{CO}_{2}$ assimilation were often misleading. When $\mathrm{CO}_{2}$ assimilation data are expressed on a per-leaf-area basis (the standard procedure in the photosynthesis literature), it is difficult to determine how photosynthetic efficiency changes as leaves or plants mature and difficult to compare the efficiency of treatments or cultivars when leaf size or total plant leaf area varies.
\end{abstract}

This paper compares the use of slope-based and ratio-based approaches to evaluate $\mathrm{CO}_{2}$ assimilation. Mathematical principles inherent in any ratio-based efficiency assessment (Atchley et al., 1976; Packard and Boardman, 1988; Pearson, 1897; Righetti et al., 2007; Tanner, 1949) were evaluated to demonstrate how ratio-based assessments of $\mathrm{CO}_{2}$ assimilation are strongly dependent on leaf size.

Net photosynthetic rates $\left(\mu \mathrm{mol} \cdot \mathrm{m}^{-2} \cdot \mathrm{s}^{-1}\right)$ are usually expressed on a leaf-area basis. When we evaluated citations in the "Photosynthesis-Source-Sink Physiology" subsection of the Journal of the American Society of Horticultural Science for 2003 and 2004, we found that all of the published papers had per-leaf-area expressions in tables or figures. Gas exchange is commonly measured either on an entire leaf or on a portion of a leaf that is enclosed in a chamber. Infrared gas analyzers connected to the sampling chamber commonly measure $\mathrm{CO}_{2}$. Net $\mathrm{CO}_{2}$ assimilation rates $\left(\mu \mathrm{mol} \cdot \mathrm{m}^{-2} \cdot \mathrm{s}^{-1}\right)$ are then calculated on a leaf-area basis. These net assimilation rates are obtained by dividing the amount of $\mathrm{CO}_{2}$ assimilated by the area of the leaf within the chamber or sampling cuvette. Chamber size and analytical approach vary in experiments measuring photosynthesis, but current systems are similar to those described years ago (Brun and Cooper, 1967). In many experiments, transpiration rates $\left(\mathrm{mmol} \cdot \mathrm{m}^{-2} \cdot \mathrm{s}^{-1}\right)$ and $g_{\mathrm{S}}$ to water vapor $\left(\mathrm{mmol} \cdot \mathrm{m}^{-2} \cdot \mathrm{s}^{-1}\right)$

Received for publication 29 June 2006. Accepted for publication 28 Sept. 2006. We thank the following mathematicians for their assistance: Leah Murphy, Oregon State University; Ricardo Baeza and Marie Ines Icaza, University of Talca; and Eric Gottlieb, Rhodes College. We also thank members of the OSU Horticulture Iconoclast Efficiency Discussion Group (Annie Chozinski, Amy Dreves, Sarah McDonald, Ellen Thompson, and Linda White) for 14 weeks of unwavering discussion on key points. We thank Wanda Parrott for editing. ${ }^{1}$ Corresponding author. E-mail: righettt@hort.oregonstate.edu. are evaluated using the same system and expressed on a leafarea basis. When per-leaf-area evaluations are multiplied by estimates of total leaf area, gas-exchange estimates of whole plants are possible.

Many researchers mistakenly believe that $\mathrm{CO}_{2}$ assimilation values for leaf areas that are measured in similar-sized sampling cuvettes are not dependent on the leaf area of the evaluated leaves. We shall argue that this is not true. Therefore, net photosynthetic rates are often dependent on leaf size when expressed on a leaf-area basis $\left(\mu \mathrm{mol} \cdot \mathrm{m}^{-2} \cdot \mathrm{s}^{-1}\right)$. We shall also argue that whole-plant photosynthetic rates can be dependent on total leaf area. From a mathematic perspective, the relationship between the area of an individual leaf and $\mathrm{CO}_{2}$ assimilation per leaf area does not change if either an entire leaf or a portion of a leaf is used to calculate $\mathrm{CO}_{2}$ assimilation per leaf area. The same argument applies to whole-plant photosynthetic rates. The relationship between average $\mathrm{CO}_{2}$ assimilation per leaf area and total leaf area does not depend on whether all leaves are measured or whether the average value determined was derived from a representative subset of individual leaves. Therefore, the leaf area for individual leaf analyses or the total leaf area for total plant analyses should always be evaluated.

Carbon dioxide assimilation per unit leaf area is one of many efficiency expressions defined as the amount of an evaluated variable divided by an amount of material associated with producing the evaluated variable. Mathematical principles apply to all ratio-based evaluations of efficiency. If a plot of the denominator vs. the numerator produces a nonzero $y$ intercept, ratios are related to their components (denominator and numerator) (Atchley et al., 1976; Packard and Boardman, 1988; Pearson, 1897; Righetti et al., 2007; Tanner, 1949). Tanner (1949) clearly stated that the use of per-weight and 
per-surface area expressions is often inappropriate because they do not account for nonzero $y$ intercepts.

Although interpreting ratio-based $\mathrm{CO}_{2}$-assimilation assessments among different cultivars, clones, or imposed treatments can be confounded by nonzero $y$ intercepts (Meinzer and Zhu, 1998; Ranjith and Meinzer, 1997; Sage and Pearcy, 1987), this concept has been ignored in much of the photosynthetic literature. It is somewhat surprising that ratio-based assessments of $\mathrm{CO}_{2}$ assimilation have become standard in the photosynthetic literature despite the published accounts cited above.

The relatively few reports that deal with a $y$-intercept problem in the photosynthetic literature involve linear relationships with negative $y$ intercepts (Meinzer and Zhu, 1998; Ranjith and Meinzer, 1997; Sage and Pearcy, 1987). This paper will present examples of difficulties associated with evaluating $\mathrm{CO}_{2}$-assimilation data when leaf size varies for linear functions with both negative and positive $y$ intercepts. Difficulties associated with curvilinear relationships between leaf area and $\mathrm{CO}_{2}$ assimilation will also be discussed. The principles discussed here apply to any ratio-based measure of efficiency.

THEORY. For all linear functions of the form $y=m x+b$, a plot of $y / x$ vs. $x$ will have the equation of $y / x=(1 / x) b+m$. For linear functions that pass through the origin $(b=0), y / x$ will be constant and equal to the slope of the original linear function. However, ratio-based expressions $(y / x)$ for linear functions that have nonzero $y$ intercepts clearly are dependent on the value of the denominator $(x)$. For photosynthetic data sets collected as leaves develop, a threshold leaf area value is often required before $\mathrm{CO}_{2}$ assimilation exceeds the $\mathrm{CO}_{2}$ release associated with plant respiration. Photosynthetic compensation points may produce plots of leaf area (or other measures of the size of photosynthetic tissues) vs. total net $\mathrm{CO}_{2}$ assimilation per leaf with negative intercepts (Meinzer and Zhu, 1998; Ranjith and Meinzer, 1997; Sage and Pearcy, 1987). This suggests that net $\mathrm{CO}_{2}$ assimilation calculated on a leaf-area basis will increase as leaf area increases.

When data are collected over a limited range of relatively large denominator sizes, linear, polynomial, or power functions can all describe experimental data. Polynomial or power functions that would bend and pass through the origin are described by near-linear relationships with positive $y$ intercepts when denominators are plotted against numerators (Righetti et al., 2007). Data variability and error can produce positive $y$ intercepts even when zero or negative intercepts are expected. Positive $y$ intercepts can also occur when subsamples are averaged or composite samples represent data trends from a larger data set (Righetti et al., 2007). Regardless of the cause, if a plot of leaf area vs. total $\mathrm{CO}_{2}$ assimilation per leaf has a positive $y$ intercept, then the net $\mathrm{CO}_{2}$ assimilation calculated on a leaf-area basis will decrease as leaf area increases. Both declining and increasing functions that describe how net $\mathrm{CO}_{2}$ assimilation calculated on a leaf-area basis changes with increasing leaf area will asymptotically approach the slope of the original linear leaf area vs. total $\mathrm{CO}_{2}$ assimilation per leaf functions.

Convex second-degree polynomial functions with negative $y$ intercepts could also describe the relationship between leaf area and total net $\mathrm{CO}_{2}$ assimilation per leaf as leaves develop. The unit gain in $y$ (total net $\mathrm{CO}_{2}$ assimilation) decreases as leaf area increases for these polynomial functions. However, when $\mathrm{CO}_{2}$ assimilation is expressed on a per-leaf-area basis, values derived from a convex second-degree polynomial function with a negative $y$ intercept will increase initially and then decline.

In addition to linear or polynomial functions with nonzero $y$ intercepts, power functions describing the relationship between denominators and numerators imply that a ratio is dependent on its denominator. The slope of a $\log -\log$ plot $\left(\log _{10} Y\right.$ vs. $\left.\log _{10} M\right)$ is often used to define the exponent of a power law in scaling studies where $Y=Y_{0} M^{b}$ (Brown and West, 2000; Kleiber, 1932; Reich et al., 2006). In the scaling literature, the variable $Y$ is some physiological or morphological characteristic, $Y_{0}$ is a scaling constant, and $M$ is often body size (Brown and West, 2000; Kleiber, 1932; Reich et al., 2006). Scaling occurs when the exponent does not equal 1.0 (Brown and West, 2000; Kleiber, 1932; Reich et al., 2006). If $b>1$, then $Y / M$ mathematically increases with body size. If $b<1$, then $Y / M$ mathematically decreases with body size. If photosynthesis scales with leaf or plant size (the relationship between $\log _{10}$ leaf area and $\log _{10}$ total $\mathrm{CO}_{2}$ assimilation per leaf or per plant is described by a power function with an exponent not equal to 1.0), then $\mathrm{CO}_{2}$ assimilation expressed on a per area basis will be dependent on leaf area.

We hypothesize that many ratio-based $\mathrm{CO}_{2}$-assimilation expressions could decline, increase, or initially increase and then decline as leaf area increases, depending on the functions that describe the relationship between leaf area and total $\mathrm{CO}_{2}$ assimilation per leaf. These ratio-based estimates of $\mathrm{CO}_{2}$ assimilation will not reflect incremental changes in efficiency as the leaf area increases. For each incremental increase in leaf area, net $\mathrm{CO}_{2}$ assimilation will generally either decline or remain constant.

Cultivars or treatments with relatively large leaf areas can theoretically have lower, higher, or the same net $\mathrm{CO}_{2}$ assimilation per leaf area as cultivars or treatments with small leaf areas, depending on the data range that is evaluated, the type of function that describes the relationship between leaf area and net $\mathrm{CO}_{2}$ assimilation per leaf, and whether the $y$ intercepts are zero, negative, or positive.

These leaf-size-related differences in photosynthetic rates generally are not accounted for in the photosynthetic literature. In the following examples, the potential errors in interpretation that result from the use of ratio-based assessments of $\mathrm{CO}_{2}$ assimilation will be explored. The mathematical phenomena discussed above are demonstrated with data from the literature and additional experimental data that we collected.

\section{Materials and Methods}

Photosynthetic Rates of Black Cherry (PRUnUs SERotina EHRH.) LEAVES WITH DIFFERENT PHYSIOLOGICAL MATURITY ON Plants WiTh THE SAME PHYSiological AGE. (Consequences of linear functions with negative $y$ intercepts). Data were taken from a published report (Horsley and Gottschalk, 1993) where the plastochron index (Erickson and Michelini, 1957; Larson and Isebrands, 1971) was used to study the relationship between leaf age and plant age on the development and net photosynthesis of black cherry grown in sand culture in plant growth chambers. Leaf area and net photosynthesis data were gathered repeatedly on plants as they grew in age from 14 to 20 plant plastochrons. Three to five plants of each plant age were used.

Net photosynthesis was measured on individual leaves in a 20-cm-diameter water-cooled, plexiglass leaf chamber with an IR gas analyzer. On each plant, net photosynthesis was 
measured on all leaves $>75 \mathrm{~mm}$, beginning with leaf number 7 (bottom). In the data presented, net photosynthesis and leaf area were shown for leaves of different physiological maturities (different leaf plastochron indices) on plants with the same physiological age (same plant plastochron index). Net photosynthesis and leaf area are presented for leaves with varying maturity on plants with plastochron indices of 14 and 20 . Efficiencies were expressed as net $\mathrm{CO}_{2}$ assimilation/leaf area $\left(\mu \mathrm{mol} \cdot \mathrm{m}^{-2} \cdot \mathrm{s}^{-1}\right)$ and plotted against leaf area. We also determined the best-fit linear function describing the relationship between leaf area and total $\mathrm{CO}_{2}$ assimilation per leaf $\left(\mu \mathrm{mol} \cdot \mathrm{s}^{-1}\right)$.

Photosynthetic rates of Black Cherry Leaves With THE SAME LEAF POSITION ON PLANTS OF DIFFERENT PHYSIOLOGICAL AGES. (Consequences of convex curvilinear functions with negative $y$ intercepts). Data were taken from the same published report (Horsley and Gottschalk, 1993) described above. Net photosynthesis and leaf area are shown for leaf numbers 7 and 13 from plants with different physiological ages. Photosynthetic efficiency was expressed as net $\mathrm{CO}_{2}$ assimilation per leaf area $\left(\mu \mathrm{mol} \cdot \mathrm{m}^{-2} \cdot \mathrm{s}^{-1}\right)$ and plotted against leaf area. The best-fit second-degree polynomial function describing the relationship between leaf area and total $\mathrm{CO}_{2}$ assimilation per leaf $\left(\mu \mathrm{mol} \cdot \mathrm{s}^{-1}\right)$ was determined. The first derivatives for the polynomial functions described above were used to evaluate incremental changes in net $\mathrm{CO}_{2}$ assimilation as leaf area increased and were compared with the standard ratio-based efficiency expressions $\left(\mathrm{CO}_{2}\right.$ assimilation per leaf area).

Photosynthetic rates of Leaves from different Wine GRAPE (VITIS VINIFERA L.) CULTIVARS. (Consequences of linear functions with positive $y$-intercepts). Data were collected from a rootstock-cultivar trial for field-grown wine grape cultivars ('Gewürztraminer' and 'Merlot') where European red mite (Panonychus ulmi Koch) infestations were monitored throughout the growing season. A portion of plants $(\approx 40 \%)$ remained mite free.

Three-year-old grapevines grafted on $5 \mathrm{C}$ ( $V$. vinifera) rootstock (Auer Baumschule, Hallau, Switzerland) were planted in 40-L pots containing loamy soil in Spring 1990. The pots were randomly sunk in an open field (to minimize temperature fluctuation on the root zone) and watered periodically with drip irrigation. Fertilizer was added to maintain optimal levels of $\mathrm{N}, \mathrm{P}, \mathrm{K}$, and $\mathrm{Mg}$, based on soil analysis. At full bloom, one shoot per plant was retained, and clusters were removed to stimulate vegetative growth. In the following season, one fruit-bearing shoot per plant was allowed to grow. The third leaf from the shoot base was used for gas-exchange and leaf-area measurements. The same leaf from individual plants was evaluated on three dates (June 15, 26, and 29), and an average value was used to represent each replicate. Similar data were collected from both mite-free $(n=8)$ and mite-infested $(n=8-11)$ plants.

Gas-exchange measurements and calculations were performed with a portable LCA-2 system (Analytical Development and Co. Ltd., Hoddesdon, Herts., England) as described by Candolfi-Vasconcelos and Koblet (1991). Leaf area of the leaves used in the gas-exchange measurements was measured after the last sampling date using an area meter (model LI-3100; LI-COR, Inc., Lincoln, Nebr.). Net $\mathrm{CO}_{2}$ assimilation per leaf area $\left(\mu \mathrm{mol} \cdot \mathrm{m}^{-2} \cdot \mathrm{s}^{-1}\right)$ and the best-fit linear functions describing the relationship between leaf area and total $\mathrm{CO}_{2}$ assimilation per leaf $\left(\mu \mathrm{mol} \cdot \mathrm{s}^{-1}\right)$ were determined from combined data from both cultivars for both mite-infested and uninfested leaves. The best-fit linear functions describing the relationship between $\log _{10}$ leaf area and $\log _{10}$ total $\mathrm{CO}_{2}$ assimilation leaf $\left(\mu \mathrm{mol} \cdot \mathrm{s}^{-1}\right)$ were determined for the same data points.

The SAS statistical package (version 9.12; SAS Institute, Cary, N.C.) was used for statistical analyses. A Bartlett's test (Barnett, 1962; Bartlett, 1937) indicated that $\mathrm{CO}_{2}$ assimilation per leaf area $\left(\mu \mathrm{mol} \cdot \mathrm{m}^{-2} \cdot \mathrm{s}^{-1}\right)$ met assumptions concerning homogeneity of variance. The PROC GLM procedure was used to conduct an analysis of variance (ANOVA) on $\mathrm{CO}_{2}$ assimilation per leaf area and to make pairwise comparisons of SAS LSMEANS. The data were analyzed as a completely randomized factorial experiment for the two cultivars with and without mites. The PROC GLM procedure was also used to conduct an analysis of covariance (ANCOVA) on $\log _{10}$ total $\mathrm{CO}_{2}$ assimilation per leaf with $\log _{10}$ leaf area as a covariate.

Homogeneity of slopes was demonstrated since covariate $x$ treatment interactions were not significant. Respective $P$ values were $0.9625,0.3814$, and 0.7394 for $\log _{10}$ leaf area $\times$ cultivar, $\log _{10}$ leaf area $\times$ mite, and $\log _{10}$ leaf area $\times$ cultivar $\times$ mite interactions. The log-transformed data were used because homogeneity of slopes was not demonstrated with the raw data. The relative importance of the different factors (leaf area, mites and cultivars) was also assessed with regression analysis.

Photosynthetic RATes OF Leaves From FRUITING AND NONFRUiting STRAWBerry (Fragaria $\times$ ananassa DUCh.) PLANTS. (Consequences of diminishing-return curvilinear functions). Data were taken from a published report (Schaffer et al., 1986b) where whole-plant photosynthetic rates for blossomed and deblossomed 'Tribute' strawberry plants were evaluated at $7-d$ intervals throughout the fruiting cycle. Plants were potted in $15-\mathrm{cm}$-diameter plastic pots and grown in the greenhouse. Five random single plant samples from each treatment were evaluated on each sampling date by enclosing whole plants in a $60-\mathrm{L}$ plexiglass chamber. Carbon dioxide depletion was determined by measuring $\mathrm{CO}_{2}$ with a Beckman model 865 IR gas analyzer (Beckman Instruments, La Habra, Calif.). Leaves, crown, roots, and fruit (when present) were harvested from each plant. Total leaf area was determined with a portable leaf area meter. Net $\mathrm{CO}_{2}$ assimilation per-leaf-area was determined at all sample times.

The best-fit second-degree polynomial and power functions describing the relationship between leaf area and total $\mathrm{CO}_{2}$ assimilation per leaf $\left(\mu \mathrm{mol} \cdot \mathrm{s}^{-1}\right)$ were determined. A $\log _{10}$ leaf area vs. $\log _{10}$ total $\mathrm{CO}_{2}$ assimilation per leaf plot was used to evaluate biological scaling and to determine whether $\mathrm{CO}_{2}$ assimilation scales differently as leaf area increases for fruiting and nonfruiting plants. This information was also used to model how $\mathrm{CO}_{2}$ assimilation per leaf area would theoretically differ for fruiting and nonfruiting plants at each sampling date.

\section{Results and Discussion}

Photosynthetic Rates of Black Cherry Leaves With DIFFERENT PHYSIOLOGICAL MATURITY ON PLANTS WITH THE SAME PHYSIOLOGICAL AGE. (Consequences of linear functions with negative $y$ intercepts). There are two different interpretations of how $\mathrm{CO}_{2}$ assimilation changes as leaves mature, depending on whether one uses a ratio-based or slope-based assessment of $\mathrm{CO}_{2}$ assimilation. Figure 1A shows the relationship between leaf area and total net $\mathrm{CO}_{2}$ assimilation per leaf for leaves with 

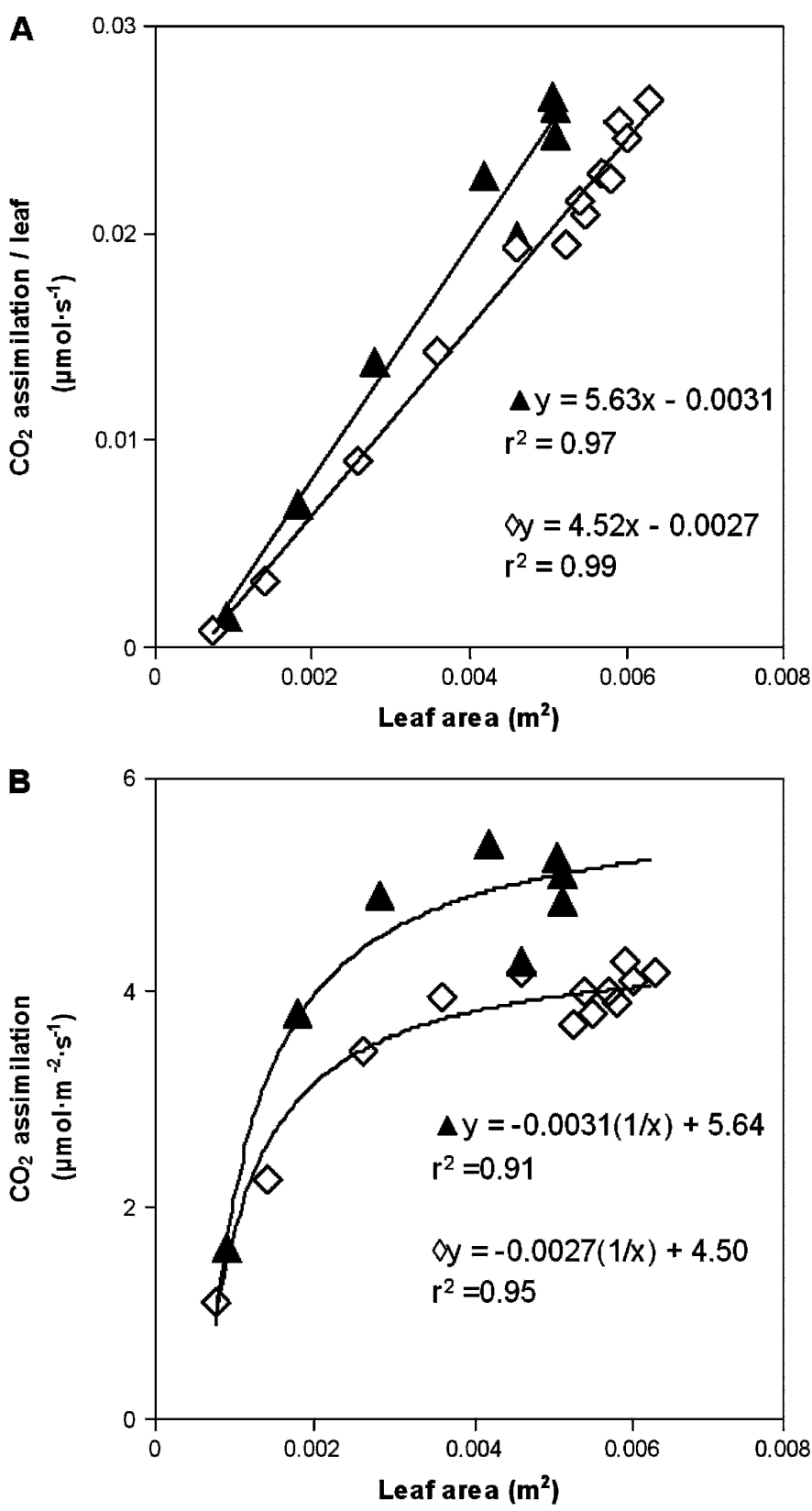

Fig. 1. (A) Relationship between leaf area and total net $\mathrm{CO}_{2}$ assimilation per leaf $\left(\mu \mathrm{mol} \cdot \mathrm{s}^{-1}\right)$ for leaves with different physiological maturity on black cherry plants with the same physiological age. Plant plastochron indices of $(\Delta) 14$ and $(\diamond) 20$ are shown. (B) Relationship between net $\mathrm{CO}_{2}$ assimilation $\left(\mu \mathrm{mol} \cdot \mathrm{m}^{-2} \cdot \mathrm{s}^{-1}\right)$ for leaves with different physiological maturity on black cherry plants with the same physiological age, calculated as the standard ratio-based expression. Interpreted from data of Horsley and Gottschalk (1993).

different physiological maturities on plants with the same physiological age. The relationship between leaf area and total $\mathrm{CO}_{2}$ assimilation for leaves of different ages on plants with plastochron ages of 14 and 20 is shown. For both plant ages, a linear function with a negative intercept describes the relationship between leaf area and total net $\mathrm{CO}_{2}$ assimilation. The linear functions suggest that, for each unit increase in leaf area, a constant increase in $\mathrm{CO}_{2}$ assimilation will occur. Slopes decline as plant plastochron age increases from 14 to 20 . This suggests that younger plants are more efficient.
When $\mathrm{CO}_{2}$ assimilation is expressed as the standard perleaf-area expression, net photosynthesis increases as leaf area increases (Fig. 1B). This occurs because leaf area is a component of both the $x$ and $y$ axes, and the original linear functions describing the relationship between $x$ (total leaf area) and $y$ (total $\mathrm{CO}_{2}$ assimilation per leaf) have negative $y$ intercepts. The $1 / x$ functions that describe the relationship between leaf area and net photosynthesis produce efficiencies asymptotically approaching values about equal to the slopes in the corresponding linear functions presented in Fig. 1A. Younger plants have a higher net $\mathrm{CO}_{2}$-assimilation rate plateau. Although net $\mathrm{CO}_{2}$ assimilation per square meter increases with leaf area, it does not necessarily follow that leaves become more efficient as leaf area increases. Although most investigations of indeterminate deciduous woody plants have found that the maximum net photosynthesis expressed on a leaf-area basis is coincidental with or just before full leaf expansion (Dickmann, 1971; Dickmann et al., 1975; Furukawa, 1973; Sams and Flore, 1982), it also does not necessarily follow that there is a large efficiency increase as leaf area increases. In this example, total net $\mathrm{CO}_{2}$ assimilation is linearly related to leaf area, and the incremental increase in $\mathrm{CO}_{2}$ assimilation as leaf area increases is constant (Fig. 1A).

If leaf areas differ when different plant or leaf ages are compared, interpretation can be complex. Small leaves will be less efficient than large leaves, but these differences depend on the range of leaf sizes that is evaluated. For example, declining leaf area in the plateau region of Fig. 1B does not have the same consequences as a decline in leaf area in a region where both leaf area and net photosynthetic rates increase.

Both ratio-based and slope-based assessments are accurate but reflect different phenomena. The ratio-based assessment increases and then reaches a plateau because a linear function with a negative $y$ intercept describes the relationship between leaf area and $\mathrm{CO}_{2}$ assimilation. Photosynthetic rates for leaf areas slightly larger than the compensation point are low because leaf-area measurements include the leaf area that was present before net $\mathrm{CO}_{2}$ assimilation occurred. At high leaf areas, the small leaf area at the compensation point becomes relatively unimportant.

PhOtosynthetic Rates of BLACK CHERRY LeAVes WITH THE SAME LEAF POSITION ON PLANTS OF DIFFERENT PHYSIOLOGICAL AGES. (Consequences of convex curvilinear functions with negative $y$ intercepts). Interpretations of how $\mathrm{CO}_{2}$ assimilation of leaves with the same leaf position on plants with different physiological ages changes as leaf area increases also depend on whether one uses a ratio-based or a slope-based assessment of photosynthetic efficiency. In Fig. 2A, the relationship between leaf area and total net $\mathrm{CO}_{2}$ assimilation for leaves with the same leaf position on plants with different physiological ages is shown. The relationship between photosynthesis per $\mathrm{m}^{2}$ and leaf area for leaf numbers 7 and 13 is shown. For both leaf positions, a convex second-degree polynomial with a negative intercept describes the relationship between leaf area and total net $\mathrm{CO}_{2}$ assimilation per leaf. The convex seconddegree polynomial functions suggest that, as leaf area increases, net $\mathrm{CO}_{2}$ assimilation also increases, but with a declining rate. Leaf number 13 (further from the bottom of the plant) has a higher net $\mathrm{CO}_{2}$ assimilation at large leaf areas than leaf number 7 , suggesting that large younger leaves are more efficient than large older leaves. At small leaf areas, $\mathrm{CO}_{2}$-assimilation rates for both leaf positions are more similar. 

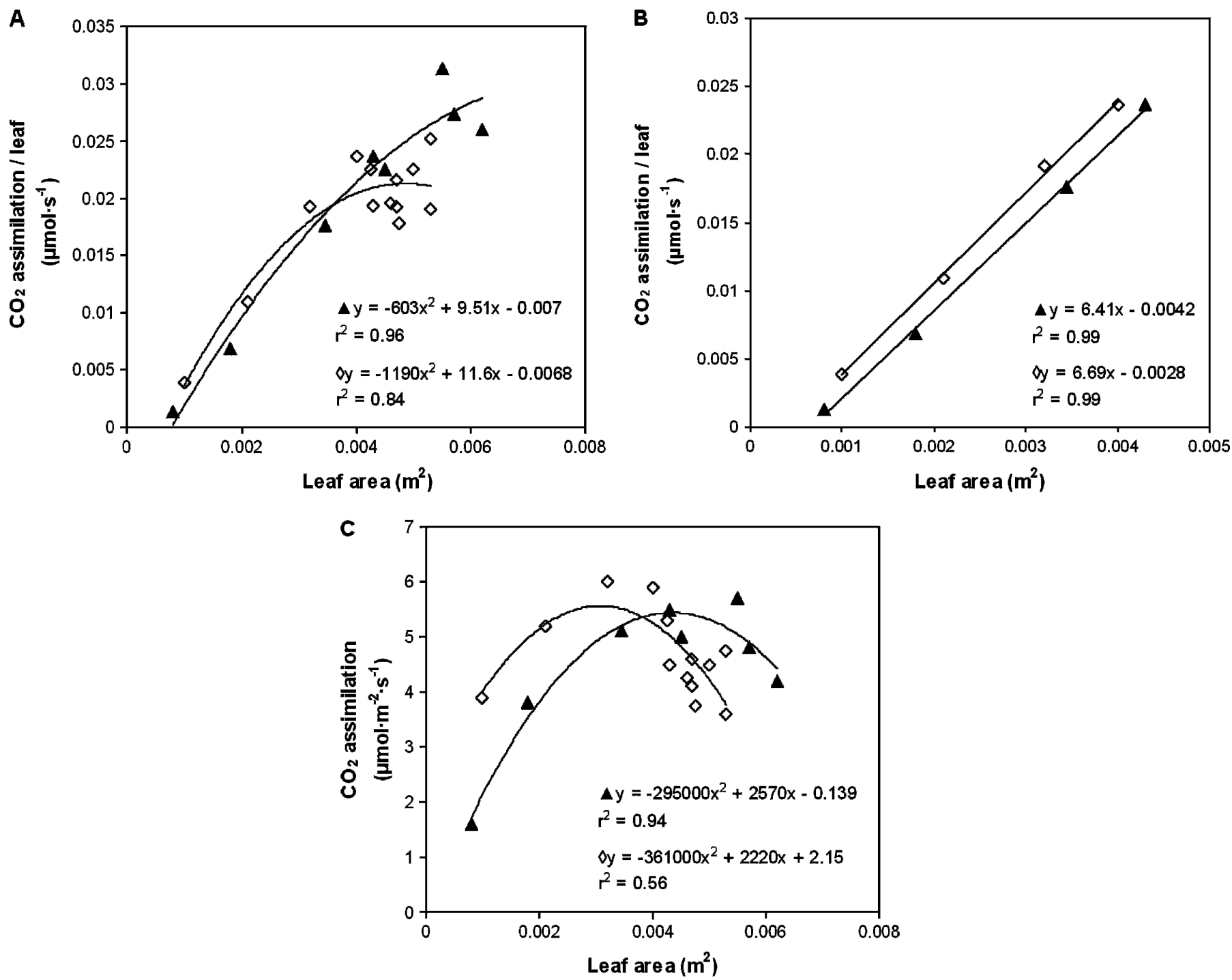

Fig. 2. (A) Relationship between leaf area and total net $\mathrm{CO}_{2}$ assimilation per leaf $\left(\mu \mathrm{mol} \cdot \mathrm{s}^{-1}\right)$ for the same leaf positions on black cherry plants with different physiological ages. Leaf numbers (starting from the bottom of the plant) $(\diamond) 7$ and $(\boldsymbol{\Lambda}) 13$ are shown. (B) Relationship between leaf area and total net $\mathrm{CO}_{2}$ assimilation per leaf $\left(\mu \mathrm{mol} \cdot \mathrm{s}^{-1}\right)$ for the same leaf positions on black cherry plants with different physiological ages for the initial linear range (first four points) of the data presented in (A). (C) Relationship between net $\mathrm{CO}_{2}$ assimilation $\left(\mu \mathrm{mol} \cdot \mathrm{m}^{-2} \cdot \mathrm{s}^{-1}\right)$ and total leaf area for the same leaf positions on black cherry plants with different physiological ages, calculated as the standard ratio-based expression. Interpreted from data of Horsley and Gottschalk (1993).

At small leaf areas, linear functions describe the relationship between leaf area and total net $\mathrm{CO}_{2}$ assimilation per leaf (Fig. 2B). Both leaf positions produce nearly parallel functions but differ in their negative $y$ intercepts. When $\mathrm{CO}_{2}$ assimilation is expressed on a leaf-area basis, net photosynthesis initially increases and then declines as leaf area increases (Fig. 2C). Photosynthetic rates for leaf 7 (older leaves) are initially higher and peak at a lower leaf area than for leaf 13. Differences are greatest for the smallest leaves, within the linear range (shown in Fig. 2B) because the transformed curves will eventually reach a similar plateau. At small-leaf areas, there are large differences in $\mathrm{CO}_{2}$ assimilation expressed on a leaf-area basis, even though nearly parallel functions describe the relationship between leaf area and total net $\mathrm{CO}_{2}$ assimilation (Fig. 2B). As the functions become nonlinear, $\mathrm{CO}_{2}$-assimilation rates decline.

The incremental changes (first derivative) in net $\mathrm{CO}_{2}$ assimilation per leaf are plotted against leaf area for both leaf positions in Fig. 3A. The rate of change becomes smaller as leaf position number increases, suggesting that the diminishing returns discussed above are smaller for younger leaf positions. An evaluation of incremental change also suggests that the older leaves are initially more efficient than younger leaves, but differences are much less than what is suggested by the ratiobased (Fig. 2C) analysis.

In Fig. 3B are presented the initial increase in net $\mathrm{CO}_{2}$ assimilation per square meter and subsequent decrease predicted from the equations shown in Fig. 2A. In all cases where a convex curvilinear function with a negative $y$ intercept describes the relationship between total $\mathrm{CO}_{2}$ assimilation per leaf and leaf area, net $\mathrm{CO}_{2}$ assimilation per square meter will increase and then decline as leaf area increases. However, this does not necessarily suggest that physiological changes cause leaves to become initially more efficient followed by decreasing efficiency as leaf area increases. Photosynthetic efficiency actually incrementally decreases. It is possible that a sigmoid curve rather than a seconddegree polynomial function represents the relationship between 

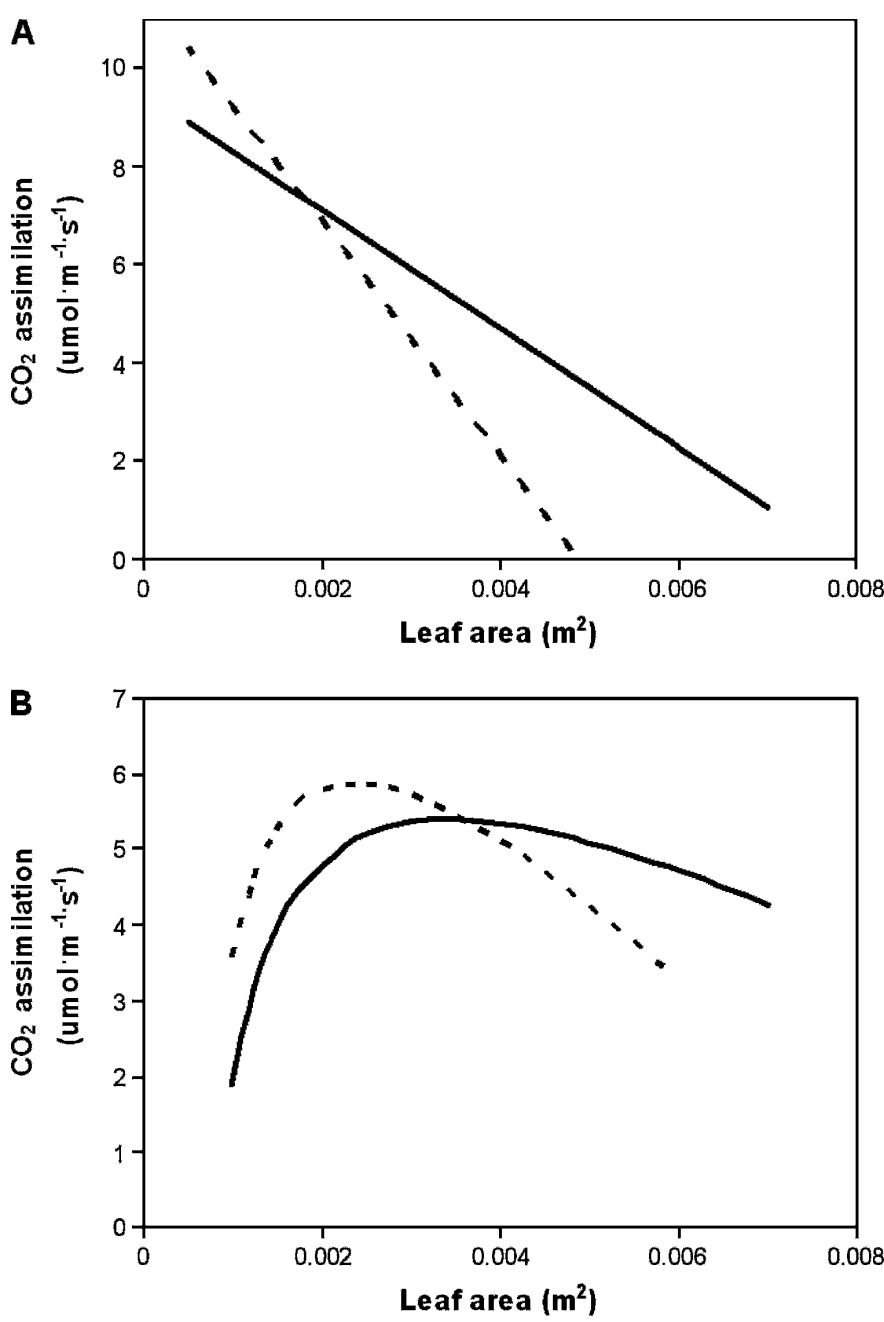

Fig. 3. (A) Relationship between leaf area and incremental changes (first derivative) for net $\mathrm{CO}_{2}$ assimilation $\left(\mu \mathrm{mol} \cdot \mathrm{m}^{-2} \cdot \mathrm{s}^{-1}\right)$ as leaf area increases for leaf number 7 (- -) and leaf number 13 (-) on black cherry plants with different physiological ages. (B) Relationship between leaf area and net $\mathrm{CO}_{2}$ assimilation $\left(\mu \mathrm{mol} \cdot \mathrm{m}^{-2} \cdot \mathrm{s}^{-1}\right)$ as leaf area increases for the same leaf positions calculated from the polynomial equations presented in Fig. 2A. Interpreted from data of Horsley and Gottschalk (1993).

total leaf area and total $\mathrm{CO}_{2}$ assimilation per leaf presented in Fig. 2A and that efficiency does initially increase, but this cannot be demonstrated with the current level of data points.

Photosynthetic Rates of Leaves From difFerent Wine GRAPE CULTIVARS. (Consequences of linear functions with positive $y$ intercepts). The ANOVA suggests that differences associated with mite infestation $(P<0.0001)$ and cultivar $(P=$ $0.001)$ were statistically significant. There was not a mite $\times$ cultivar interaction $(P=0.7395)$. If one outlier is dropped from the analysis (discussed below), probability levels for the mite effect and interaction remain similar but the cultivar probability level declines $(P=0.0002)$. However, the ANOVA does not necessarily suggest that cultivars differ in $\mathrm{CO}_{2}$ assimilation efficiency. The statistical differences between cultivars could be indirect. 'Gewürztraminer' could have higher assimilation rates than 'Merlot' simply because it has smaller leaves rather than being physiologically more efficient.

The data in Fig. 4A reveal that a plot of total leaf area vs. total $\mathrm{CO}_{2}$ assimilation per leaf has positive intercepts for both miteinfested and mite-free conditions. The slopes of the two lines are not significantly different. However, in an ANCOVA analyzing total $\mathrm{CO}_{2}$ assimilation per leaf with total leaf area as a covariate, the total leaf area $\times$ mite interaction is significant $(P=0.0377)$ suggesting that mite-infested leaves assimilate $\mathrm{CO}_{2}$ less efficiently. Although the intercept is only significantly different from zero for the mite-infested conditions $(P<0.05)$, the trends for both cultivars suggest that $\mathrm{CO}_{2}$ assimilation expressed on a leaf-area basis could decrease as leaf area increases.

The $\log _{10}$ leaf area vs. $\log _{10}$ total $\mathrm{CO}_{2}$ assimilation per leaf plots in Fig. 4B suggest that power functions with exponents $<1$ also describe the data. Although the slope is only significantly $<1(P<0.05)$ for the mite-infested conditions, the trends for both cultivars again suggest that $\mathrm{CO}_{2}$ assimilation expressed on a leaf-area basis could decrease as leaf area increases.

In Fig. 4C the relationship between $\mathrm{CO}_{2}$ assimilation expressed on a leaf-area basis and total leaf area is presented. Carbon dioxide assimilation significantly declines as leaf area increases for both mite-infested and mite-free conditions when an outlier is removed from the mite-free data set. Packard and Boardman (1988) proposed using the denominator of a ratiobased expression as a covariate when analyzing the numerator to eliminate indirect effects associated with differently sized denominators. When an ANCOVA was conducted analyzing $\log _{10}$ total $\mathrm{CO}_{2}$ assimilation per leaf with $\log _{10}$ leaf area as a covariate, significant cultivar effects disappear $(P<0.094)$. However, mite and covariate effects (leaf area) remain significant $(P<0.034$ and $P<0.0001$, respectively). If data without the outlier are analyzed, cultivar effects still disappear $(P<0.110)$ and the mite and covariate effects remain significant $(P<0.035$ and $P<0.0001$, respectively). A regression model that predicts total $\mathrm{CO}_{2}$ assimilation per leaf using leaf area as a quantitative variable and mites, cultivar, and mite $\times$ cultivar interaction as qualitative variables ( 0 or 1$)$ revealed that only leaf area and mite effects were statistically significant $(P<0.05)$. Combining leaf area and mite effects explains $79 \%$ of the variability in total $\mathrm{CO}_{2}$ assimilation per leaf. The presence or absence of mites explains $54 \%$ of the variability in total $\mathrm{CO}_{2}$ assimilation per leaf.

Figure 4D is a diagrammatic presentation demonstrating how the means of $\mathrm{CO}_{2}$ assimilation per leaf area for the two cultivars depend on leaf area. Mean values for the four treatments have been superimposed on the functions predicting the relationship between $\mathrm{CO}_{2}$ assimilation per leaf area and leaf area derived from the equations presented in Fig. 4A and B. The ANCOVA and regression analyses support the graphical presentation in Fig. 4A, suggesting that the differences between cultivars are indirect and explained by differences in leaf size. The largest leaves from 'Gewürztraminer' and smallest leaves from 'Merlot' would have similar leaf areas and not be significantly different with respect to $\mathrm{CO}_{2}$ assimilation per leaf area.

It is possible that the two cultivars assimilate $\mathrm{CO}_{2}$ differently as leaf area increases. However, at the level of replication used, the slopes and intercepts for the two cultivars are not significantly different when either total $\mathrm{CO}_{2}$ assimilation per leaf vs. leaf area or $\log _{10}$ total $\mathrm{CO}_{2}$ assimilation per leaf vs. $\log _{10}$ leaf area are plotted for either mite-infested or mite-free conditions (data not shown). Trends for greater $\mathrm{CO}_{2}$ assimilation for 'Gewürztraminer' than 'Merlot' that are not statistically significant $(P \approx 0.10$ in ANCOVA) become highly significant if the ratio-based $\mathrm{CO}_{2}$ assimilation expression is used.

Photosynthetic RATES OF Leaves From FRUiting AND NONFRUITING STRAWBERRY PLANTS. (Consequences of diminishing-return curvilinear functions). When total plant leaf area is 

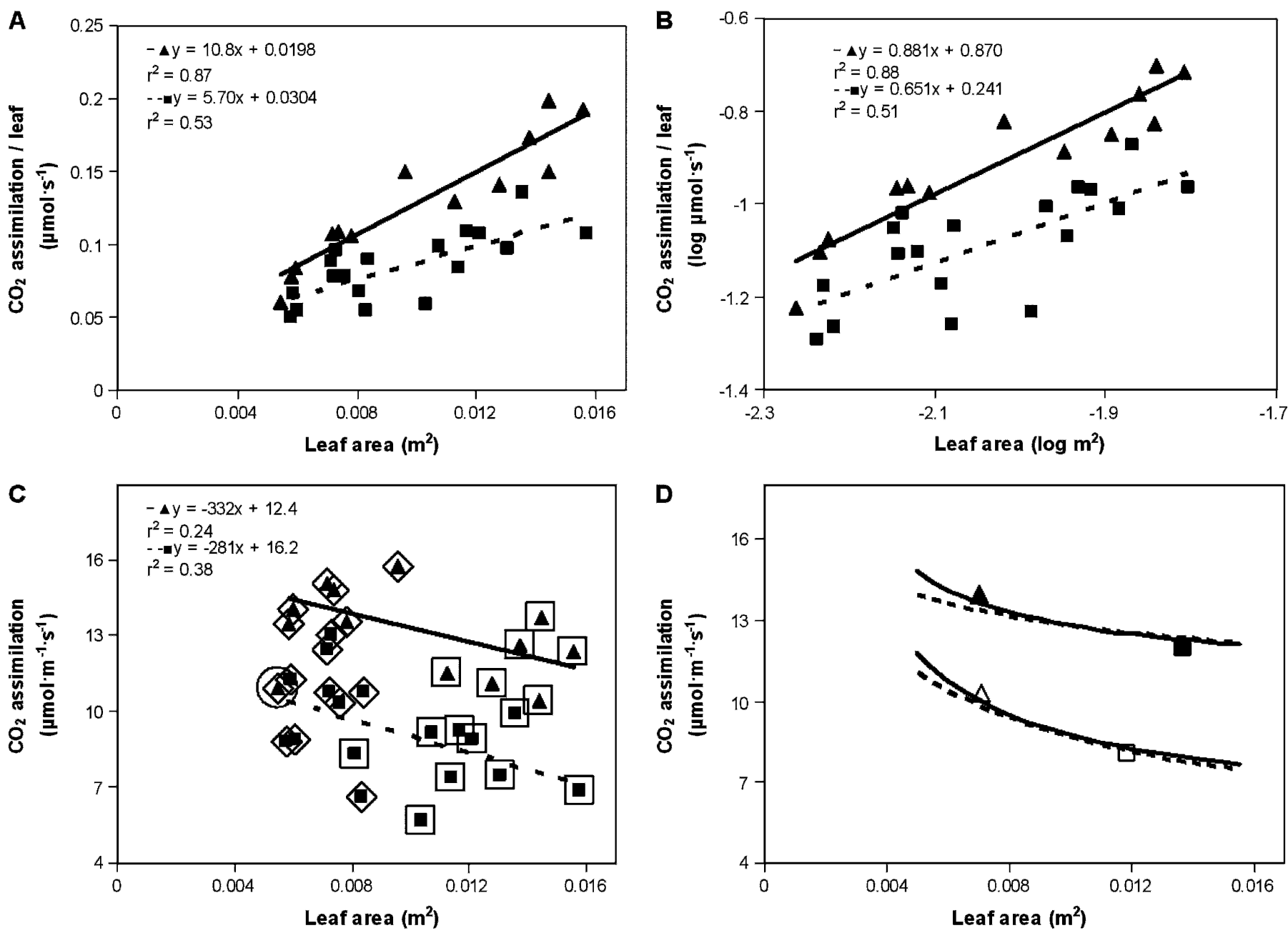

Fig. 4. (A) Relationship between leaf area and total net $\mathrm{CO}_{2}$ assimilation per leaf $\left(\mu \mathrm{mol} \cdot \mathrm{s}^{-1}\right)$ for 'Gewürztraminer' and 'Merlot' wine grape plants with $(\square)$ and without ( $\boldsymbol{\Lambda}$ ) mite infestation. (B) Relationship between $\log _{10}$ leaf area and $\log _{10}$ total net $\mathrm{CO}_{2}$ assimilation per leaf $\left(\log \mu \mathrm{mol} \cdot \mathrm{s}^{-1}\right)$ for 'Gewürztraminer' and 'Merlot' wine grape plants with $(\boldsymbol{\square})$ and without $(\boldsymbol{\Lambda})$ mite infestation. (C) Relationship between net $\mathrm{CO}_{2}$ assimilation $\left(\mu \mathrm{mol} \cdot \mathrm{m}^{-2} \cdot \mathrm{s}^{-1}\right)$ and leaf area for 'Gewürztraminer' $(\diamond)$ and 'Merlot' $(\square)$ wine grape plants with $(\boldsymbol{\square})$ and without $(\boldsymbol{\Delta})$ mite infestation. One outlier $(\square)$ is also identified. (D) Relationship between predicted net $\mathrm{CO}_{2}$ assimilation $\left(\mu \mathrm{mol} \cdot \mathrm{m}^{-2} \cdot \mathrm{s}^{-1}\right)$ and leaf area derived from the linear $(-)$ functions in $(\mathbf{A})$ and the $\log -\log (--)$ functions in $(\mathbf{B})$. Mean values for 'Gewürztraminer' with $(\Delta)$ mites, 'Gewürztraminer' without $(\boldsymbol{\Delta})$ mites, 'Merlot' with $(\square)$ mites, and 'Merlot' without mites (ロ) are shown.

plotted against total plant $\mathrm{CO}_{2}$ assimilation, a convex second degree polynomial describes the data (Fig. 5A). A power function $\left(r^{2}=0.947\right)$ also describes the relationship (data not shown). These curves reflect the fact that $\mathrm{CO}_{2}$ assimilation efficiency generally declines with increases in leaf area. Although nonfruiting plants had significantly more leaf area (Schaffer et al., 1986b), the $\log _{10}$ total plant leaf area vs. $\log _{10}$ total plant $\mathrm{CO}_{2}$ assimilation plot (Fig. $5 \mathrm{~B}$ ) suggests that the two treatments (with and without fruit) assimilate $\mathrm{CO}_{2}$ identically as leaf area increases. Slopes for the two treatments are not significantly different, and neither $y$ intercept is significantly different from zero $(P<0.05)$. The data does scale (slopes $<1.0$; $P<0.05)$. Therefore, plants with large total leaf area are less efficient than plants with small total leaf area regardless of whether larger leaf area is associated with older plants or differences between fruiting and nonfruiting plants of similar age.

In Fig. 5C, we model results based on an assumption that the relationship between leaf area and total $\mathrm{CO}_{2}$ assimilation per plant is the same for both treatments. We have used the equation derived from the combined data from both treatments to predict
$\mathrm{CO}_{2}$ assimilation per leaf area for different sampling dates. Fruiting treatments appear more efficient although the data were derived based on the assumption that the relationship between leaf area and total $\mathrm{CO}_{2}$ assimilation per plant are the same for both treatments. The pattern in these simulations is similar to what is often reported in the literature when fruiting and nonfruiting treatments are compared (Choma et al., 1982; Forney and Breen, 1985). In the original references dealing with the same experiment described in Fig. 5, $\mathrm{CO}_{2}$ assimilation per leaf area tended to be higher in fruiting plants for both young leaves (Schaffer et al., 1986a) and entire plants (Schaffer et al., 1986b). However, if the relationship between leaf area and total $\mathrm{CO}_{2}$ assimilation per plant is described by a diminishingreturn curve, and leaf areas are larger for nonfruiting plants, fruiting treatments will always appear to be more efficient.

\section{Conclusion}

A per-leaf-area assessment of photosynthetic efficiency is an accurate evaluation of the amount of net $\mathrm{CO}_{2}$ assimilation but does not necessarily reflect physiological differences among 

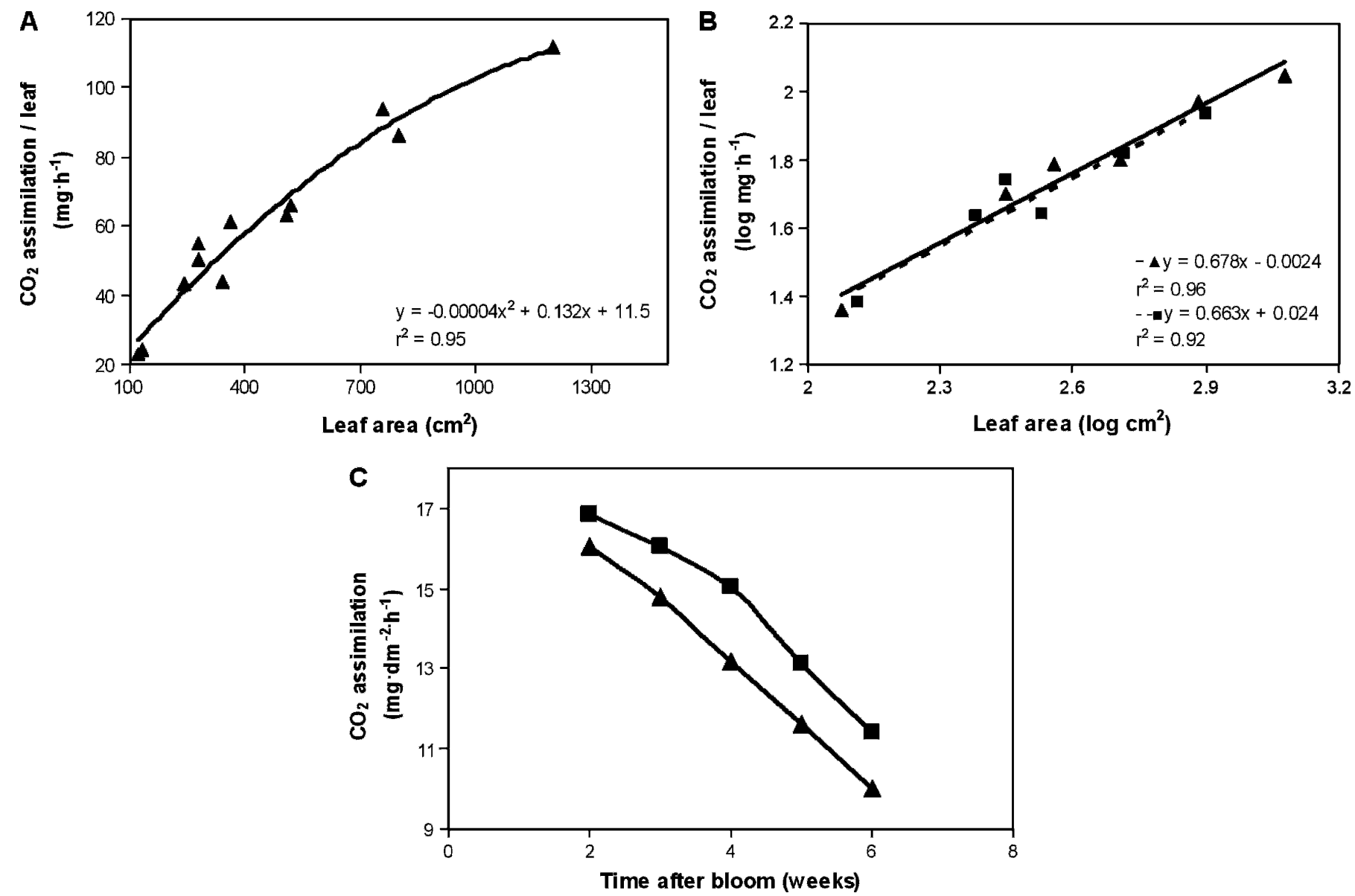

Fig. 5. (A) Relationship between total leaf area and total net $\mathrm{CO}_{2}$ assimilation per plant for combined fruiting and nonfruiting treatments evaluated on a weekly interval for entire strawberry plants. (B) Relationship between $\log _{10}$ total leaf area and $\log _{10}$ total net $\mathrm{CO}_{2}$ assimilation per plant evaluated on a weekly interval for entire strawberry plants for fruiting ( $(\boldsymbol{)})$ and nonfruiting ( $\boldsymbol{\Delta}$ ) treatments. (C) Modeled $\mathrm{CO}_{2}$ assimilation evaluated on a weekly interval for entire strawberry plants expressed on a per-leaf-area basis. The modeling process assumed that the relationship between $\log _{10} \operatorname{leaf}$ area and $\log _{10}$ net $\mathrm{CO}_{2}$ assimilation per plant was constant for both fruiting and nonfruiting treatments. $\mathrm{CO}_{2}$ assimilation $\left(\mathrm{mg} \cdot \mathrm{h}^{-1}\right)$ was predicted from an equation derived from all points representing both fruiting $(\square)$ and nonfruiting ( $\mathbf{\Lambda})$ treatments shown in (B). Interpreted from data of Schaffer et al. (1986b).

leaves of different sizes. Net photosynthesis, when expressed on a leaf-area basis, will be dependent on leaf area. If a plot of leaf area vs. total net $\mathrm{CO}_{2}$ assimilation is not described by a linear function that passes through the origin, it is not appropriate to statistically compare standard measurements of $\mathrm{CO}_{2}$ assimilation (expressed on a leaf-area basis) for differently sized leaves.

Negative intercepts for the linear or convex second-degree polynomial functions that describe the relationship between leaf area and $\mathrm{CO}_{2}$ assimilation commonly occur. Therefore, a per-leaf-area efficiency expression will often increase and then reach a plateau or initially increase and then decline as leaf area increases, when, in fact - with rare exceptions - incremental efficiency can only either remain constant or decline, respectively. The exception is the situation where concave curvilinear functions describe the relationship between leaf area and total net $\mathrm{CO}_{2}$ assimilation per leaf. In our search of the literature, we found that this occurs only rarely (data not shown).

Very large leaves are sometimes less efficient than smaller leaves (convex second-degree polynomial functions describe the relationship between leaf area and $\mathrm{CO}_{2}$ assimilation per leaf). However, leaves with relatively large leaf areas theoretically can have either the same, more, or less net photosynthesis than smaller leaves when net $\mathrm{CO}_{2}$-assimilation rates are expressed on a per-leaf-area basis. The results depend on the data range one evaluates, the type of function describing the relationship between leaf area and net $\mathrm{CO}_{2}$ assimilation per leaf, and whether the $y$ intercepts are zero, negative, or positive.

It is difficult to determine how photosynthetic performance changes as leaves mature, evaluate clones with different $\mathrm{CO}_{2}-$ assimilation patterns, and compare the efficiency of treatments or cultivars if leaf size varies in data sets where $\mathrm{CO}_{2}$ assimilation is expressed per unit leaf area. It may be more appropriate to collect data over a wide range of leaf sizes and evaluate how total $\mathrm{CO}_{2}$ assimilation per leaf varies rather than to compare more narrowly defined leaf types (leaf position, plastochron index, etc.) when evaluating differences among cultivars, clones, or treatments. Differences in the distribution of leaf sizes and in the relationship between leaf area and total $\mathrm{CO}_{2}$ assimilation per leaf must be understood to interpret differences among cultivars, clones, or treatments. Per-leaf-area assessments of $\mathrm{CO}_{2}$ assimilation may still be useful, but both direct and leaf-area-related indirect effects must be clarified.

Determining how $\mathrm{CO}_{2}$ assimilation changes in response to changes in leaf area is also important for whole plant evaluations. Unless this is done, it will be difficult to determine 
whether treatment, time, or cultivar differences are due to real physiological changes in leaf performance or simply reflect the general decline in $\mathrm{CO}_{2}$ assimilation per-leaf-area often observed as the total leaf area increases. In the individual leaf and wholeplant examples described above, leaf-area data were available. Unfortunately, in many reports, leaf-area data are not presented, and it is difficult to fully evaluate experimental results. Statistical approaches that account for differences in leaf size should be used when evaluating $\mathrm{CO}_{2}$-assimilation data expressed on a per-leaf-area basis. Several approaches have been proposed.

\section{Literature Cited}

Atchley, W.R., C.T. Gaskins, and D. Anderson. 1976. Statistical properties of ratios. I. Empirical results. Syst. Zool. 25:137-148.

Barnett, V.D. 1962. Large sample tables of percentage points for Hartley's correction to Bartlett's criterion for testing the homogeneity of a set of variances. Biometrika 49:487-494.

Bartlett, M.S. 1937. Some examples of statistical methods of research in agriculture and applied biology. J.R. Stat. Soc. Ser. A Suppl. 4:137-170.

Brown, J.H. and G.B. West. 2000. Scaling and biology. Oxford University Press, New York.

Brun, W.A. and R.I. Cooper. 1967. Effects of light intensity and carbon dioxide concentration on photosynthetic rate of soybean. Crop Sci. $7: 452-454$.

Candolfi-Vasconcelos, M.C. and W. Koblet. 1991. Influence of partial defoliation on gas exchange parameters and chlorophyll content of field-grown grapevines. Mechanisms and limitations of the compensation capacity. Vitis 30:129-141.

Choma, M.E., J.L. Garner, R.P. Marini, and J.A. Barden. 1982. Effects of fruiting on net photosynthesis and dark respiration of 'Hecker' strawberries. HortScience 17:212-213.

Dickmann, D.I. 1971. Photosynthesis and respiration by developing leaves of cottonwood (Populus deltoides Bartr.). Bot. Gaz. 132:253-259.

Dickmann, D.I., D.H. Gjerstad, and J.G. Gordon. 1975. Developmental patterns of $\mathrm{CO}_{2}$ exchange, diffusion resistance and protein synthesis in leaves of Populus Xeuramericana, p. 171-181. In: R. Marcelle (ed.). Environmental and biological control of photosynthesis. Dr. W. Junk, Publishers, The Hague, Netherlands.

Erickson, R.O. and F.J. Michelini. 1957. The plastochron index. Amer. J. Bot. 44:297-305.
Forney, C.F. and P.J. Breen. 1985. Dry matter partitioning and assimilation in fruiting and deblossomed strawberry. J. Amer. Soc. Hort. Sci. 110(2):181-185.

Furukawa, A. 1973. Photosynthesis and respiration in poplar plant in relation to leaf development. J. Jpn. For. Sci. 55:119-123.

Horsley, S.B. and K.W. Gottschalk. 1993. Leaf area and net photosynthesis during development of Prunus serotina seedlings. Tree Physiol. 12:55-69.

Kleiber, M. 1932. Body size and metabolism. Hilgardia 6:315-353.

Larson, P.R. and J.G. Isebrands. 1971. The plastochron index as applied to developmental studies of cottonwood. Can. J. For. Res. $1: 1-11$.

Meinzer, F.C. and J. Zhu. 1998. Nitrogen stress reduces efficiency of the $\mathrm{C}_{4} \mathrm{CO}_{2}$ concentrating system, and therefore quantum yield, in Saccharum (sugarcane) species. J. Expt. Bot. 49:1227-1234.

Packard, G.C. and T.J. Boardman. 1988. The misuse of indices and percentages in ecophysiological research. Physiol. Zool. 61:1-9.

Pearson, K. 1897. On a form of spurious correlation which may arise when indices are used in the measurement of organs. Proc. R. Soc. London 60:489-502.

Ranjith, S.A. and F.C. Meinzer. 1997. Physiological correlates of variation in nitrogen-use efficiency in two contrasting sugarcane cultivars. Crop Sci. 37:818-825.

Reich, P.B., M.G. Tjoelker, J.L. Machado, and J. Oleksyn. 2006. Universal scaling of respiratory metabolism, size and nitrogen in plants. Nature 439:457-461.

Righetti, T.L., D.R. Sandrock, B. Strik, C. Vasconcelos, S. Ortega, Y. Moreno, and P. Banados. 2007. Analysis of ratio-based responses. J. Amer. Soc. Hort. Sci. 132:3-13, 2007.

Sage, R.F. and R.W. Pearcy. 1987. The nitrogen use efficiency of $\mathrm{C}_{3}$ and $\mathrm{C}_{4}$ plants. Plant Physiol. 84:959-963.

Sams, C.E. and J.A. Flore. 1982. The influence of age, position, and environmental variables on net photosynthesis rate of sour cherry leaves. J. Amer. Soc. Hort. Sci. 107:339-344.

Schaffer, B., J.A. Barden, and J.M. Williams. 1986a. Net photosynthesis, dark respiration, stomatal conductance, specific leaf weight, and chlorophyll content of strawberry plants as influenced by fruiting. J. Amer. Soc. Hort. Sci. 111(1):82-86.

Schaffer, B., J.A. Barden, and J.M. Williams. 1986b. Plant photosynthesis and dry-matter partitioning in fruiting and deblossomed dayneutral strawberry plants. J. Amer. Soc. Hort. Sci. 111(3):430-433.

Tanner, J.M. 1949. Fallacy of per-weight and per-surface area standards and their relation to spurious correlation. J. Appl. Physiol. 2:1-15. 